DEUTSCHE AKADEMIE DER WISSENSGHAFTEN ZU BERLIN

\title{
Wörterbuch
}

$\mathbf{Z u}$

\section{Goethes Werther}

\author{
von \\ Erna Merker \\ VIERTE/FUNFTE LIEFERUNG \\ liebenswürdig bis übel \\ unter Mitwirkung von \\ Elisabeth Linke \\ bearbeitet von \\ Isabel Engel, Johanna Graefe, \\ Josef Mattausch, Fritz Merbach
}

A K A D E M I E - V E R L A G B E R L I N

1965 